\title{
Catheter Balloon Adjustment of the Pulmonary Artery Band: Feasibility and Safety
}

\author{
Howaida El-Said • Rabih Hamzeh • John Lamberti • \\ John Moore
}

Received: 1 May 2010/Accepted: 18 September 2010/Published online: 31 October 2010

(C) The Author(s) 2010. This article is published with open access at Springerlink.com

\begin{abstract}
The study aimed to assess the feasibility and safety of increasing pulmonary artery band (PAB) diameter by catheter-based PAB balloon dilation (PABBD). Eight dilations were performed between October 2006 and December 2008. Hemoclips were used to fix PABs surgically in a procedure designed to permit progressive clip dislodgment in a controlled manner. The PABBD resulted in gradual band loosening until the desired physiologic state was achieved. At time of PABBD, the patients had a mean age of 6 months (range 3-14 months) and a mean weight of $5 \mathrm{~kg}$ (range $2.6-7.3 \mathrm{~kg}$ ). The median time from PAB placement until PABBD was 4.5 months (range 1-9 months). The single-balloon technique was used in seven cases (serial dilations in 5 cases) and the doubleballoon technique in one case. The PABBDs were successful for all the patients, who experienced a mean saturation increase of 75-89\% $(P=0.01)$ (mean increase of $20 \%)$, a mean PAB gradient decrease from 69 to $36 \mathrm{mmHg}$ $(P=0.002)$ (mean decrease of $49 \%)$, and a mean band site diameter increase from 4.1 to $6.1 \mathrm{~mm}(P=0.01)$ (mean increase of $45 \%)$. The only complication was transient
\end{abstract}

H. El-Said $(\bowtie) \cdot J$. Moore

Department of Pediatric Cardiology, Rady Children's Hospital, University of California, San Diego, San Diego, CA, USA

e-mail: hgelsaid@yahoo.com

R. Hamzeh

Department of Cardiology, Baylor College of Medicine,

Texas Children's Hospital, Houston, TX, USA

J. Lamberti

Department of Cardiothoracic Surgery, University of California,

San Diego, San Diego, CA, USA pulmonary edema in one patient. The PABBD procedure is a feasible and safe method for increasing pulmonary blood flow in a staged manner and may eliminate the need for surgical band removal in some cases.

Keywords Congenital heart disease · Pulmonary artery band P Palliation

In the modern era, primary complete repair of congenital heart defects is considered optimal. In certain situations such as those involving premature infants or complex defects, such as multiple ventricular septal defects (VSDs) associated with complex arch and great vessel anatomy $[8,9]$, palliative management to reduce pulmonary blood flow with a pulmonary artery band (PAB) $[12,14]$ may be a safer option than complete repair during the neonatal period. A key consideration with respect to PAB placement, however, is that the band will become more restrictive as the patient grows, causing diminished pulmonary blood flow and progressive cyanosis. This situation has traditionally required surgical intervention with early repair and "debanding" that may include pulmonary artery patch plasty or surgical band "loosening."

In the late 1980s and early 1990s, several authors described various methods of nonsurgical debanding, both in vitro and in vivo $[1,10,13,16,18]$. Technical considerations, however, have led authors to hypothesize that although cumbersome tools hinder the procedure, the development of more user-friendly equipment may confer greater practicality to the process [2]. Interventional debanding has not been revisited in recent years, but recent improvements in catheter, wire, and balloon design have made the prospect of interventional $\mathrm{PAB}$ loosening more feasible. 
This study aimed to review our series of percutaneous PAB balloon dilations (PABBDs) with a focus on patient selection and technical aspects.

\section{Methods and Cases}

\section{Technique of PAB Placement}

The pericardium was opened, and a plane between the aorta and the pulmonary artery was dissected. The adventitial dissection was limited to the space necessary for placement of a band around the pulmonary artery when possible. We used polytetrafluoroethylene (PTFE) braided tape (Bard Peripheral Vascular, Tempe, AZ, USA). Infants received 2-mm bands, and larger children received wider bands. A temporary pressure-monitoring catheter was placed in the distal main pulmonary artery. If a patent ductus arteriosus was present, it was ligated, and the effect on the pulmonary artery pressure was noted.

The band was progressively tightened by adding medium ligaclips (Ethicon Endosurgery, LLC, J\&J, NJ, USA), while monitoring the systemic arterial pressure, distal pulmonary arterial pressure, and peripheral arterial oxygen saturation. Blood gases also were measured at appropriate intervals. When the appropriate hemodynamic state was achieved, the band was secured to the pulmonary artery by placement of 6-0 Prolene (Ethicon Inc) sutures on opposite sides of the equator of the proximal pulmonary artery as far in posterior direction possible (Fig. 1a). No sutures were placed at the site of band apposition (anteriorly) (Fig. 1c). This method of clipping and posterior fixation permits the balloon dilation to cause slippage of the clips over the PTFE during dilation (Fig. 1b).
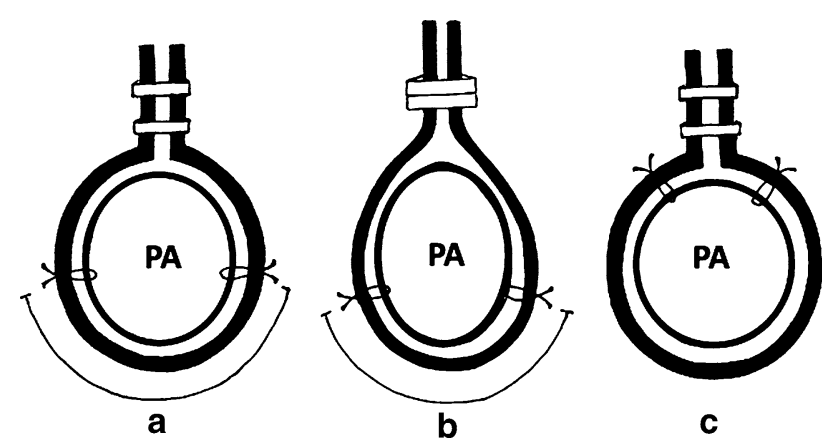

Fig. 1 Pictorial representation of the position of the pulmonary artery band (PAB), clips, and sutures. a The sutures are positioned on opposite sides of the equator of the proximal pulmonary artery, as far as possible in the posterior direction. b Balloon dilation of he PAB causes slippage of the clips over the polytetrafluoroethylene (PTFE). c The more frequently used method pictured earlier entails fixing the band by sutures anteriorly near the site of band apposition, and thus precludes balloon dilation
A more frequently used method that entails fixing the band by sutures near the site of band apposition essentially precludes PABBD because dilation requires breaking the sutures to enlarge the pulmonary artery diameter. The consequences are unpredictable and may entail risk of pulmonary artery rupture.

\section{Technique of PAB Balloon Dilation}

\section{Single-Balloon Technique}

After appropriate hemodynamic measurements, an angiogram was performed with the catheter tip in the right ventricle or the main pulmonary artery (MPA) proximal to the PAB. Measurements of the pulmonary valve annulus (PVA) and the MPA in the lateral projection determined the maximum balloon size that could be used. Serial dilations, starting with a smaller balloon, allowed for more controlled band dilation, thus preventing overexpansion that could lead to pulmonary overcirculation and vessel rupture (Figs. 2, 3).

The initial balloon selected was 1-2 mm larger than the angiographic band diameter. Serially larger balloons, not exceeding the diameter of the PVA or MPA, were selected.

After initial measurements were taken, a guidewire was placed distally into the pulmonary vasculature of either branch pulmonary artery using an end-hole catheter such as a balloon wedge catheter or a 4-Fr angled Glidecatheter (Terumo Medical Corporation, Somerset, NJ, USA). The guidewire of choice was dependent on the catheter internal lumen of the chosen balloon. A 0.035-in. Wholey Hi-Torque Floppy guidewire (Mallinckrodt Inc., St. Louis, MO, USA), a 0.014-in. Balance MiddleWeight guidewire (Guidant Corporation, Santa Clara, CA, USA), or a 0.035-in. Teflon wire (Cook Medical Inc, Bloomington, IN, USA) was used. The chosen balloon then was passed over the wire and inflated to the desired atmospheric pressure based on the manufacturer's suggested guidelines.

Noncompliant balloons were used for all the patients except one to allow for titration of the minimum atmospheric pressure necessary to abolish the waist on the balloon. In one case (patient 4a in Table 1), only 1 month after $\mathrm{PAB}$ placement in a $2.6-\mathrm{kg}$ premature infant, it was thought that the use of a compliant balloon might be safer. This approach achieved adequate dilation and an appropriate increase in saturation. However, as the patient continued to grow and become progressively more cyanotic, a noncompliant balloon was needed for the second PABBD.

After PAB dilation and loosening, the balloon catheter was removed, leaving the wire in its distal position, and arterial saturation was measured. If the desired saturation was not attained, a larger balloon was selected for further $\mathrm{PAB}$ loosening. This process was repeated until the desired 
Fig. 2 (case 3 in Table 2) The main pulmonary artery (MPA) is demonstrated in the lateral projection before and after balloon dilation, with an increase in the diameter of the pulmonary artery band (PAB) site from 4.4 to $6.3 \mathrm{~mm}$. Note the change in the orientation of the second clip
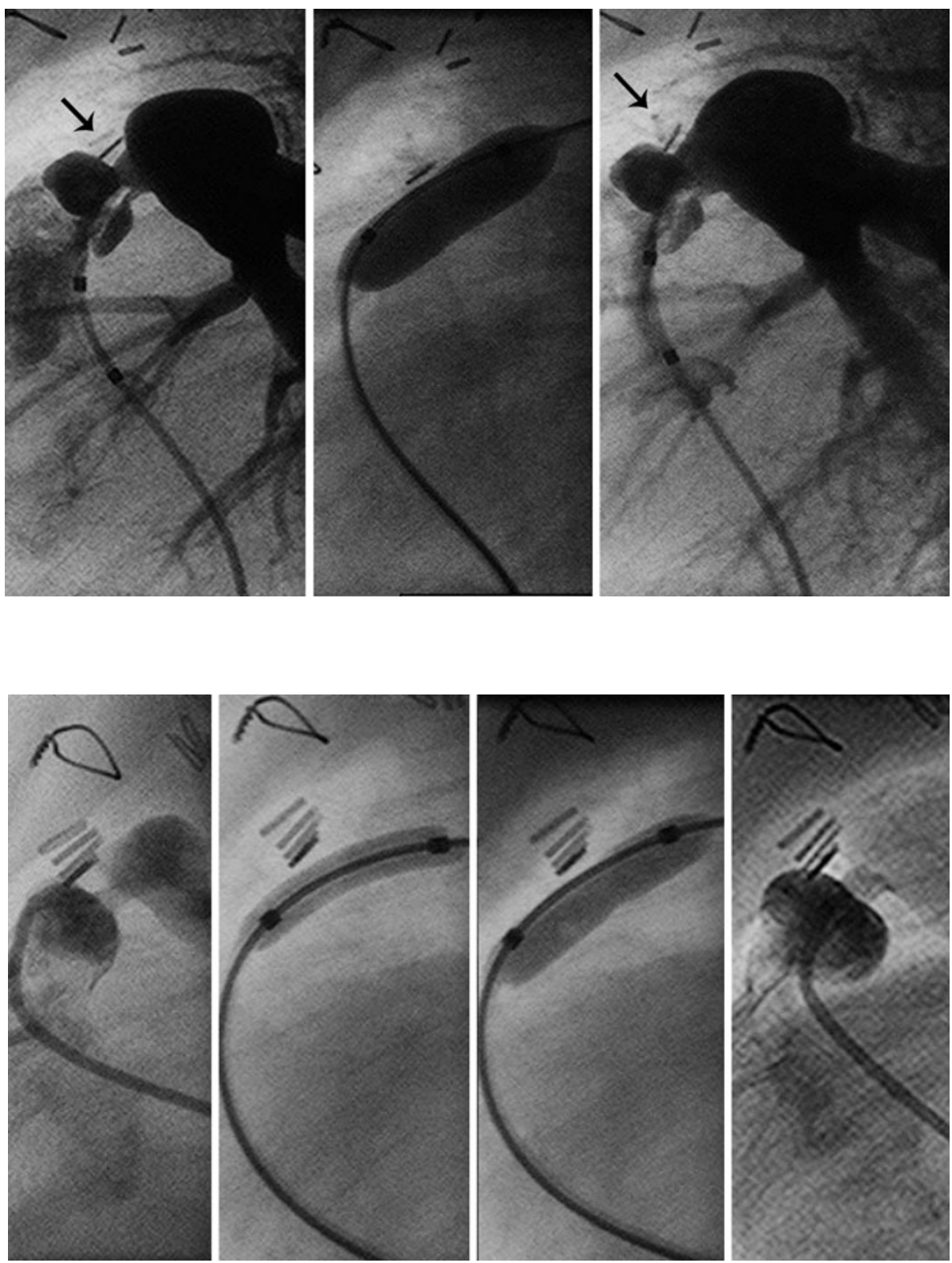

Fig. 3 (case 4 in Table 2) The main pulmonary artery (MPA) is shown in the lateral projection after serial dilations using a 4-mm balloon followed by a 5-mm balloon, with an increase in the diameter of the pulmonary artery band (PAB) site from 3.1 to $4.2 \mathrm{~mm}$ saturation was achieved, with the upper limit balloon size not exceeding that of the MPA or PVA. After the final dilation, the balloon was removed, and a pigtail catheter was advanced over the wire into the main pulmonary artery to perform a final angiogram (Figs. 3, 4).

\section{Double-Balloon Technique}

For one patient, it was noted that distal PAB migration had resulted in proximal branch pulmonary artery stenosis. Therefore, a double-balloon technique was used, with cannulation of both branch pulmonary arteries using two end-hole catheters. The balloon sizes used were equal to the distal branch pulmonary artery measurements beyond the stenoses. This technique allowed for adequate PAB dilation without the use of a single balloon too large for either pulmonary artery branch (Fig. 5).

Procedural success was defined as safe and controlled serial PABBDs that resulted in the target saturation without injury to the MPA or PVA. However in case 6 (see the Results section), the intended result was complete removal of the PAB and angioplasty of the branch pulmonary arteries rather than an increase in saturation.

\section{Statistical Methods}

All analyses were conducted using Microsoft Office Excel 2003 statistical software (Microsoft Corporation, Redmond, WA, USA). Means and standard deviations are reported for 
Table 1 Demographics and diagnosis of the 6 cases

\begin{tabular}{|c|c|c|c|c|c|c|c|}
\hline Case & $\begin{array}{l}\text { Birth } \\
\text { weight } \\
(\mathrm{kg})\end{array}$ & $\begin{array}{l}\text { Age at } \\
\text { PABB } \\
\text { (months) }\end{array}$ & $\begin{array}{l}\text { Weight } \\
(\mathrm{kg})\end{array}$ & $\begin{array}{l}\text { Time } \\
\text { from } \\
\text { PAB } \\
(\mathrm{mos})\end{array}$ & Diagnosis/surgery & $\begin{array}{l}\text { Noncardiac } \\
\text { diagnosis }\end{array}$ & Follow-up \\
\hline 1 & 4.8 & 4 & 6.3 & 4 & $\begin{array}{l}\text { DORV, d-mal GVs, sub-AS, arch hypoplasia/arterial } \\
\text { switch operation \& PAB }\end{array}$ & & $\begin{array}{l}\text { Glenn at } 8 \text { months and a } \\
\text { Rastelli at age of } \\
3 \text { years }\end{array}$ \\
\hline 2 & NA & 14 & 7.3 & 2 & CoA, large apical muscular VSD/arch repair \& PAB & & Residual VSD/rebanded $^{\mathrm{a}}$ \\
\hline $3 a$ & \multirow[t]{2}{*}{2.2} & 3 & 3.3 & 3 & \multirow{2}{*}{$\begin{array}{l}\text { Heterotaxy, LV dominant unbalanced AVC, mixed } \\
\text { obstructed TAPVR, common atrium/TAPVR repair } \\
\text { \& PAB }\end{array}$} & & \multirow{2}{*}{$\begin{array}{l}\text { Stable saturations, no } \\
\text { other intervention }\end{array}$} \\
\hline $3 b$ & & 9 & 7.3 & 9 & & & \\
\hline $4 \mathrm{a}$ & \multirow[t]{2}{*}{1.4} & 4 & 2.6 & 1 & \multirow[t]{2}{*}{ CoA, multiple muscular VSDs/arch repair \& PAB } & \multirow{2}{*}{$\begin{array}{l}\text { 33-week premie/ } \\
\text { Down } \\
\text { syndrome }\end{array}$} & \multirow{2}{*}{$\begin{array}{l}\text { VSD patch closed } \\
8 \text { months later }\end{array}$} \\
\hline $4 b$ & & 6 & 3.6 & 3 & & & \\
\hline 5 & 2.27 & 3 & 3.8 & 3 & CoA, large apical muscular VSD/arch repair \& PAB & $\begin{array}{l}\mathrm{CDH} / \text { lung } \\
\text { disease/vent } \\
\text { dependent }^{\mathrm{b}}\end{array}$ & $\begin{array}{l}\text { Died of CLD } 2 \text { months } \\
\text { later }\end{array}$ \\
\hline 6 & 2.6 & 6 & 6.1 & 6 & CoA, large apical muscular VSD/arch repair \& PAB & $\begin{array}{l}\text { Townes Brock } \\
\text { syndrome }^{c}\end{array}$ & Small residual VSD \\
\hline
\end{tabular}

${ }^{a}$ Residual VSD/rebanded: VSD device removed secondary to impaired diastolic function 2 weeks later and PAB replaced

${ }^{b}$ After repair, could not be weaned off of ventilation and died of CLD (chronic lung disease)

${ }^{c}$ Townes Brock syndrome (absent radius, webbed neck, absent left kidney)

$P A B B$ pulmonary artery band balloon, $P A B$ pulmonary artery band, $D O R V$ double outlet right ventricle, $d$-mal $G V s$ d-malposition of the great vessels, sub-AS subaortic stenosis, $N A$ not available, $C o A$ coarctation of the aorta, VSD ventricular septal defect, $L V$ left ventricle, $A V C$ atrioventricular canal defect, $T A P V R$ total anomalous pulmonary venous return $C D H$ congenital diaphragmatic hernia, $C L D$ chronic lung disease

all continuous variables. Student's paired $t$-test was used for probability.

\section{Results}

Between October 2006 and December 2008, the described technique of $\mathrm{PAB}$ placement was used for all patients who
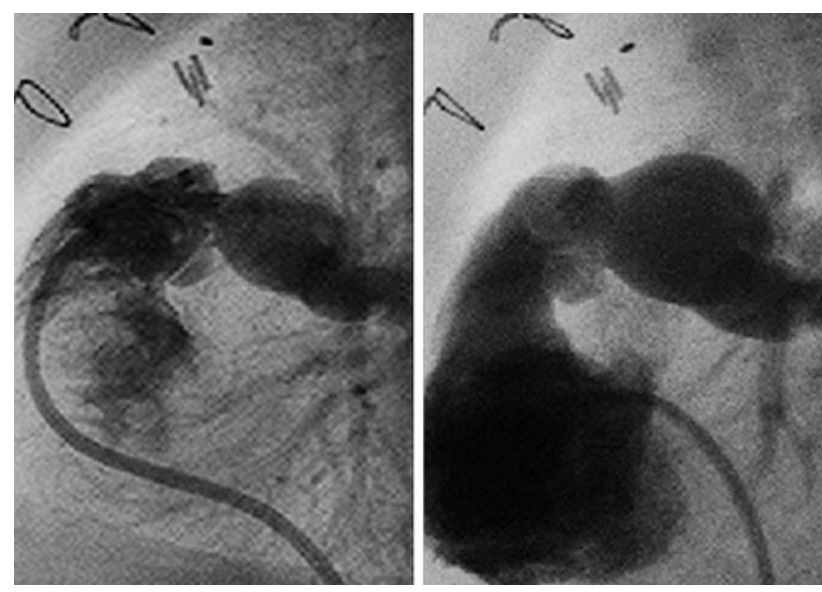

Fig. 4 (case 5 in Table 2) The main pulmonary artery (MPA) is demonstrated in the lateral projection before and after balloon dilation. Note that the band site after dilation has approximately the same diameter as the pulmonary annulus, with poststenotic dilation distal to it required a $\mathrm{PAB}$ placement regardless of the indication for banding. Of the 49 patients who received PAB placement, 6 underwent eight PABBDs (2 patients underwent the procedure twice) (Table 1). At the time of catheterization, the patients had a mean age of 6 months (range 3-14 months) and a mean weight of $5 \mathrm{~kg}$ (range $2.6-7.3 \mathrm{~kg}$ ). The median time from $\mathrm{PAB}$ placement was 4.5 months (range 1-9 months).

The two diagnoses that required $\mathrm{PAB}$ placement among our patients were coarctation of the aorta $(\mathrm{CoA}) /$ transverse aortic arch hypoplasia with multiple apical muscular VSDs $(n=4)$ and functional single ventricle with unprotected pulmonary blood flow $(n=2)$. The single-balloon PABBD technique was used in seven of the eight cases. Five patients required serial dilations, and two patients reached the desired saturation after the first balloon dilation (Table 2).

The double-balloon PABBD was used for one patient, as previously described, with intent for both $\mathrm{PAB}$ removal and branch pulmonary artery angioplasty. The balloon diameters used ranged from 4 to $12 \mathrm{~mm}$. The ratios of the initial balloon diameter to the minimum diameter at the site of the $\mathrm{PAB}$ using the single-balloon technique ranged from 1.25 to 1.64. Case 6 was an exception because the double technique was used with balloons sized to perform both debanding and adequate branch pulmonary artery angioplasty. 

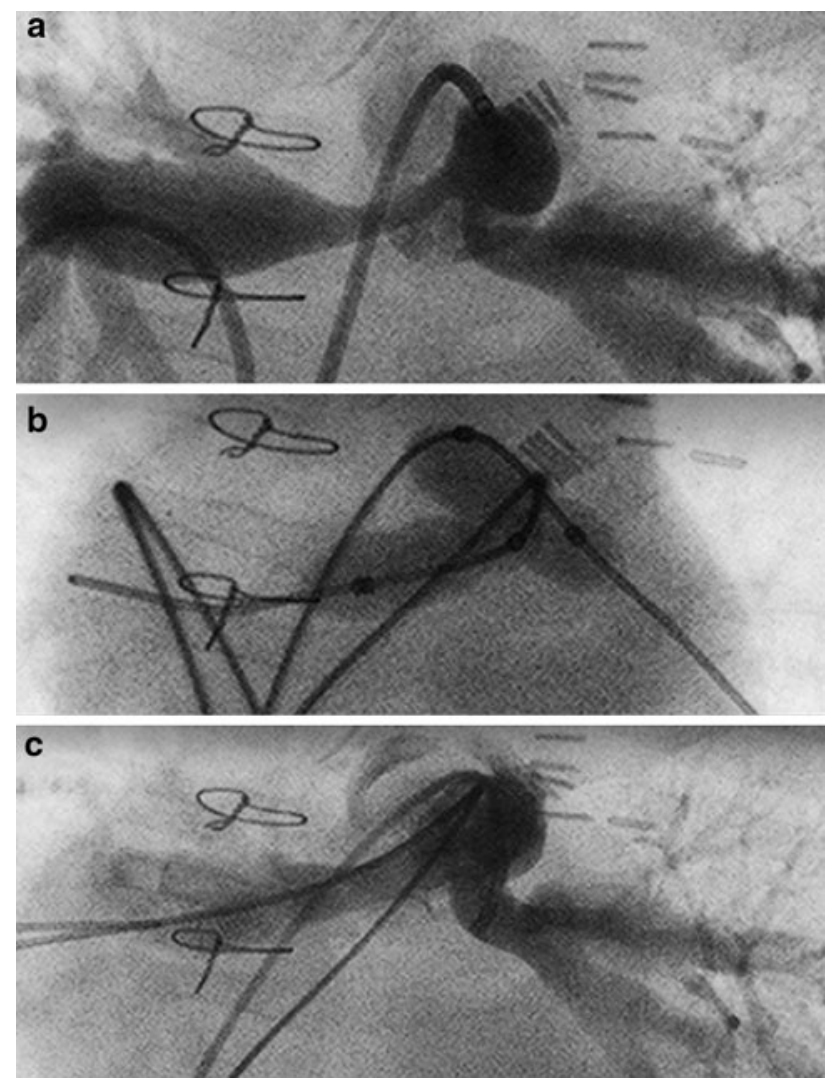

Fig. 5 (case 6 in Table 2) The double-balloon technique for balloon dilation of the pulmonary artery band (PABBD) is shown in a case of bilateral branch stenoses. a An angiogram in the caudal angulation displays severe bilateral branch stenoses due to band distal migration. b Two 8-mm balloons are inflated simultaneously in both branches. c Follow-up angiography shows improved caliber of both branch pulmonary arteries after bilateral balloon dilation

The mean initial balloon diameter-to-minimum diameter ratio among the single balloon technique cases was $1.37 \pm 0.17$. The ratio of the final balloon diameter to the initial minimum diameter at the $\mathrm{PAB}$ ranged from 1.33 to
1.64 (included in this range are the initial balloon sizes if only one balloon was used for PABBD) (mean $1.56 \pm 0.16$ ). The ratio of the initial balloon diameter to the MPA or PVA diameter (whichever was less) ranged from 0.42 to 0.77 (mean $0.57 \pm 0.14$ ). The ratio of the final balloon diameter to the MPA or PVA diameter (whichever was less) was $0.48-0.85$ (included in this range are initial balloon sizes if only one balloon was used for PABBD) (mean $0.64 \pm 0.14$ ).

All procedures were successful, as defined in the Methods and Cases section. Systemic saturation increased from a mean of $75 \pm 11$ to $89 \pm 9 \%(P=0.01)$, representing a mean increase of $20 \pm 11 \%$. The gradient across the $\mathrm{PAB}$ decreased from a mean of $69 \pm 11 \mathrm{mmHg}$ to a mean of $36 \pm 15 \mathrm{mmHg}(P=0.002)$, representing a mean decrease of $49 \pm 17 \%$ (procedures 1 and 2 were omitted because postdilation gradients were not obtained). The band-site diameter increased from a mean of $4.1 \pm 1.5 \mathrm{~mm}$ to a mean of $6.1 \pm 2.0 \mathrm{~mm}(P=0.01)$, representing a mean increase of $45 \pm 7 \%$. One patient had acute pulmonary edema requiring mechanical ventilation for 5 days. No other procedure-related complications occurred. The mean follow-up period was 1.6 years (range 1.8-3.5 years). The details of the follow-up evaluation are listed in Table 1. Two representative cases are discussed in more detail in the following sections.

\section{Case 4: PAB Ballooned Twice}

A male Down's syndrome infant of 33 weeks gestation with transverse aortic arch hypoplasia and multiple muscular VSDs underwent arch repair and PAB at the age of 2 months.

\section{First Balloon Dilation}

At 4 months of age (2 months after PAB placement) the infant boy, weighing $2.6 \mathrm{~kg}$, underwent PABBD secondary

Table 2 Catheterization data

\begin{tabular}{|c|c|c|c|c|c|c|c|c|c|}
\hline \multirow[t]{2}{*}{ Case } & \multirow{2}{*}{$\begin{array}{l}\text { PVA } \\
(\mathrm{mm})\end{array}$} & \multirow{2}{*}{$\begin{array}{l}\text { MPA } \\
(\mathrm{mm})\end{array}$} & \multicolumn{2}{|c|}{ Narrow (mm) } & \multicolumn{2}{|c|}{ Gradient $(\mathrm{mmHg})$} & \multicolumn{2}{|c|}{ Saturations (\%) } & \multirow{2}{*}{$\begin{array}{l}\text { Balloon } \\
(\mathrm{mm})\end{array}$} \\
\hline & & & Before & After & Before & After & Before & After & \\
\hline 1 & 9.6 & 8.2 & 4.5 & 7 & 67 & NM & 67 & 76 & $6-7$ \\
\hline 2 & 9.8 & 12.3 & 4 & 5.7 & 80 & NM & 70 & 88 & $5-6$ \\
\hline $3 a$ & 8.3 & 8.8 & 3 & 4.2 & 73 & 38 & $62^{\mathrm{a}}$ & $85^{\mathrm{a}}$ & 4 \\
\hline $3 b$ & 11.3 & 13.4 & 4.4 & 6.3 & 76 & 36 & $60^{\mathrm{a}}$ & $78^{\mathrm{a}}$ & $7-8$ \\
\hline $4 a$ & 9.3 & 8.7 & 3.1 & 4.2 & 73 & 47 & 87 & 96 & $4-5$ \\
\hline $4 b$ & 13 & 11.9 & 4.2 & 6.3 & 45 & 21 & $89^{\mathrm{a}}$ & $98^{\mathrm{a}}$ & $5-6$ \\
\hline 5 & 15.6 & 16.5 & 7.3 & 11 & 58 & 10 & 79 & 98 & 12 \\
\hline 6 & 16 & 16 & $2.7 / 2.4^{\mathrm{b}}$ & $5.3 / 6^{\mathrm{b}}$ & 75 & $54 / 43^{\mathrm{b}}$ & 83 & 90 & $8+8$ \\
\hline
\end{tabular}

a With $100 \%$ oxygen

${ }^{\mathrm{b}}$ Left pulmonary artery (LPA)/right pulmonary artery (RPA)

$P V A$ pulmonary valve annulus, $M P A$ main pulmonary artery, $N M$ not measured 
to saturations in the 70's and suprasystemic right ventricular pressures by echocardiography, suggesting that the VSDs had become restrictive. The PVA measured $9.3 \mathrm{~mm}$; the MPA measured $8.7 \mathrm{~mm}$; and the PAB site measured $3.1 \mathrm{~mm}$. Because the VSDs were believed to be restrictive, it was thought that the patient's final desired saturation should be in the upper 90's. Dilation was performed initially using a Tyshak miniballoon (B/Braun Medical Inc. Bethlehem, PA, USA), size $4 \mathrm{~mm} \times 2 \mathrm{~cm}$, inflated (6 atm) over an 0.014 Hi-Torque Floppy guidewire, followed by further ballooning with a Tyshak miniballoon (6 atm), size $5 \mathrm{~mm} \times 2 \mathrm{~cm}$ (Fig. 3). The gradient across the PAB decreased from 78 to $40 \mathrm{mmHg}$, and the systemic saturation increased from 75 to $96 \%$. The most narrow area at the site of the band increased from 3.1 to $4.2 \mathrm{~mm}$.

\section{Second Balloon Dilation}

At the age of 6 months ( 3 months after the PAB), the boy, weighing $3.6 \mathrm{~kg}$, was referred for further $\mathrm{PAB}$ dilation due to saturations in the 60 's. Echocardiography showed the development of pulmonary vein stenosis, with a mean gradient of 5-6 mmHg in all four pulmonary veins. The PVA measured $13 \mathrm{~mm}$; the MPA measured $11.9 \mathrm{~mm}$; and the PAB site measured $4.2 \mathrm{~mm}$. A Power Xtreme balloon (Johnson \& Johnson, Cordis Corporation, Miami, FL, USA), size $5 \mathrm{~mm} \times 2 \mathrm{~cm}$, over a $0.035 \mathrm{in}$. Teflon wire (20 atm) was used. The gradient across the PAB decreased from 45 to $35 \mathrm{mmHg}$, and the saturation increased to $89 \%$.

Further balloon dilation was performed using a Power Xtreme balloon, size $6 \mathrm{~mm} \times 2 \mathrm{~cm}$, over the same wire (24 atm). The gradient further decreased from 35 to $21 \mathrm{mmHg}$, and the saturation increased from 89 to $98 \%$. The most narrow area at the site of the band increased from 4.2 to $6.3 \mathrm{~mm}$. During this catheterization, focal pulmonary vein stenosis at the entrance into the left atrium was confirmed.

At the age of 8 months of age, the boy underwent VSD closure, pulmonary artery debanding, patch reconstruction, and pulmonary vein stenosis repair. At this writing, the patient is doing well, with mild residual pulmonary vein stenosis.

\section{Case 6: Double-Balloon Technique}

A double-balloon technique was performed for a male infant with multiple medical problems including Townes Brock syndrome, vertebral anomalies, severe scoliosis, absent right radius, webbed neck, absent left kidney, transverse arch hypoplasia, tunnel subaortic stenosis, and an unrestrictive high muscular VSD. He underwent arch repair and $\mathrm{PAB}$ placement at the age of 5 days. When the boy was 6 months age and weighed $6.1 \mathrm{~kg}$, echocardiography showed that the VSD had become smaller, with moderate branch pulmonary artery stenoses due to distal
PAB migration and encroachment onto the pulmonary artery bifurcation.

Because the VSD had likely become restrictive and the PAB was contributing to the development of branch pulmonary artery stenoses, it was decided that the best course of action would be complete removal of the band. A double-balloon technique was therefore used to perform both angioplasty of the branch pulmonary arteries and complete debanding. The right pulmonary artery (RPA) measured $2.7 \mathrm{~mm}$ proximally and $6.4 \mathrm{~mm}$ distally, and the left pulmonary artery (LPA) measured $2.4 \mathrm{~mm}$ proximally and $8 \mathrm{~mm}$ distally (Fig. 5a). The PVA measured $16 \mathrm{~mm}$, and the MPA measured $16 \mathrm{~mm}$. The Qp:Qs was 0.75:1. The right ventricular pressure was systemic, and the PAB gradient was $75 \mathrm{mmHg}$ into the right pulmonary artery with a systemic saturation of $83 \%$.

The RPA was cannulated first. With cannulation of the LPA, pulmonary blood flow was diminished, as evidenced by decreasing systemic saturations and blood pressure, so no LPA measurements were performed. Two Powerflex balloons size $8 \mathrm{~mm} \times 2 \mathrm{~cm}$ were placed simultaneously across the distally migrated PAB and within each branch pulmonary artery over 0.035 -in. Teflon wires. Both balloons then were inflated at the same time to $15 \mathrm{~atm}$ (Fig. 5b).

After ballooning, the gradients from the MPA into the right and left pulmonary arteries were 43 and $54 \mathrm{mmHg}$, respectively, with distal mean pressures measuring 25 and $30 \mathrm{mmHg}$, respectively. Systemic saturations increased from $83 \%$ to $90 \%$, and the Qp:Qs increased to $1.26: 1$. The most narrow area of the RPA increased from 2.7 to $5.3 \mathrm{~mm}$ and that of the LPA from 2.4 to $6 \mathrm{~mm}$ (Fig. 5c).

The patient remained intubated for 5 days due to acute pulmonary edema from rapid increase in pulmonary blood flow. He recovered uneventfully and was discharged from the hospital 2 weeks later. He was initially managed medically for mild pulmonary overcirculation for 3 months, after which medications were weaned off due to further VSD restriction. When the boy was 21 months of age, echocardiography showed further improvement in the branch pulmonary artery stenosis, with MPA to RPA and LPA gradients measuring 7 and $13 \mathrm{mmHg}$, respectively. In retrospect, the VSD was less restrictive than initially suggested by echocardiography, and serial dilations could have been performed to avoid pulmonary edema.

\section{Discussion}

Effects of Balloon Dilation of PAB on the Pulmonary Artery

The short-term experience of early surgical debanding (e.g., hybrid procedure for hypoplastic left heart syndrome) 
suggests that most pulmonary arteries are not significantly scarred or distorted after banding for several months. Similarly, our procedure involves a "subacute" debanding (after months), rather than a "chronic" debanding (after years). Thus, the rationale behind PAB loosening within a few months of initial placement was based on the speculation that the pulmonary artery may be enlarged at the band site without disruption of the arterial wall and that by increasing the diameter of the band through serial balloon dilations, the vessel may be expanded toward its normal diameter.

The application of relatively small radial forces allows for gradual loosening of the band from its initial diameter by dislodging the surgical clips used to secure it. This technique permits the use of progressively larger balloons as required while the balloon waist and both clip movement and dislodgment are observed to monitor the impact of balloon dilation.

\section{Technique and Safety of PABBD}

Chosen balloon sizes are limited by the angiographic pulmonary artery diameter and the pulmonary annulus diameter. Initially, a balloon diameter 1 to $2 \mathrm{~mm}$ larger than the angiographic band diameter is used. Balloon diameters are gradually increased to achieve the desired physiologic effects. The more recent availability of many small-diameter, low-profile, and compliant angioplasty balloons has made this feasible. We believe that this conservative, sequential technique for band enlargement provides a margin of safety from vessel tears or dissections. Furthermore, the availability of low-profile, $7 \times 22-\mathrm{mm}$ Atrium covered stents (CAST covered stent; Atrium Medical Corporation, Hudson, NH, USA), which may be mounted on larger balloons if required, provides an interventional rescue option for catastrophic vessel rupture. No obvious pulmonary artery vessel damage has been encountered in our patients, and we believe that the risk of vessel tear or dissection is low.

Our study findings show that PABBD can be performed safely and effectively. The procedure was successful for all the patients who underwent the procedure with the intent of increasing baseline saturations without complications. The procedure also was applied successfully for our patient who underwent the double-ballooning technique to attain complete debanding due to significant obstruction on the branch pulmonary arteries. Although this patient subsequently experienced a transitory period of pulmonary edema, the procedure was considered successful because the significant branch pulmonary artery stenoses were effectively addressed as intended.
Adjustable PABs

Several reports describe the successful use of adjustable bands, but notable considerations exist that may preclude their routine use. Adjustment of PAB using the telemetric adjustable FloWatch-PAB pneumatic device (EndoArt, Lausanne, Switzerland) through an external control unit has been reported. The authors of the report detailed simpler postoperative management and shorter intensive care unit (ICU) stays. They concluded that the $\$ 10,000$ cost of the device was outweighed by a savings in hospital expense [4, 6, 7, 15]. This device was studied in Europe and currently is not FDA approved for use in the United States. Although the reported results showed promise, the authors thought their study did not prove clinical efficacy of the FloWatch-PAB compared with standard approaches. Furthermore, placement of this device mandates additional surgery for eventual removal. This could be an unattractive option in certain scenarios such as cases of multiple VSDs that may require only temporary $\mathrm{PAB}$ until the VSDs close or become hemodynamically insignificant. Finally, a significant complication has been reported by Venugopal et al. [17] and Michel-Behnke et al. [11] in which implantation of the FloWatch-PAB device led to pulmonary artery transection and pseudoaneurysm formation 6 and 7 weeks after implantation.

Choudhary et al. [5] described creating an adjustable PAB using Ethibond suture, a ligaclip, and PTFE with externalization of the sutures to allow for PAB fine-tuning in the immediate postoperative period. The sutures then are internalized before hospital discharge, thus rendering additional PAB modifications impossible without further surgery. This technique is potentially useful early after surgery but is not a long-term solution.

Bonnet et al. [3] advocated the placement of a PAB made from bioabsorbable materials. Although this is a very attractive option requiring no further intervention, the duration of banding is not adjustable. With a fixed mean banding duration of 5.7 months (range 3-6.5 months), this system becomes limited when clinicians are dealing with the dynamic physiology of congenital heart disease of the young child.

\section{Catheter-Based PAB Dilation}

The technique of catheter-based PAB loosening or debanding was reported as early as 1990. However, technical considerations limited the procedure. Difficulties with the manipulation of large balloon catheters (8-Fr) and stiff balloons led the authors to postulate that whereas the procedure is hampered by cumbersome tools, the development of more precise equipment may render the procedure 
feasible [2]. Currently, with the availability of softer, more responsive and kink-resistant catheters as well as improved more flexible wires and lower-profile more compliant balloons, this technique has become more feasible. However, concerns still exist about catastrophic acute ruptures, tears, false aneurysms, and dissections, which may complicate the use of this technique.

We have performed a PABBD method that allows minimally invasive dilation or loosening by catheter balloon dilation. We report eight successful procedures in six cases, with one complication. For all the patients, we were able to achieve increased pulmonary blood flow when clinically appropriate, and in four cases, no further intervention for the pulmonary artery band was needed.

Our method for balloon dilation of the PAB was based on titration of the band diameter to a specific desired saturation. This was accomplished using a balloon diameter 1-2 mm larger than the minimal diameter of the band, not exceeding the diameter of the PVA or the MPA, whichever was smaller. For our patients in whom the single-balloon technique was used, this approach alleviated cyanosis with the initial chosen balloon in two cases and required upsizing once in the remaining five cases. The mean ratio of the final balloon required for the desired saturation to the minimal diameter at the PAB was $1.56 \pm 0.16$. Thus, perhaps a further refinement of our method for choosing a balloon would be to opt for a balloon approximately 1.4-1.7 times the minimal diameter. Also, the mean final balloon diameter was $64 \pm 14 \%$ of the PVA or MPA (whichever was least) in our patients, thus allowing for effective and selective dilation of the PAB while minimizing significant disruption of surrounding structures.

The aforementioned parameters led to an increase in saturations of $20 \pm 11 \%$ and a decrease in the gradient across the PAB of $49 \pm 17 \%$, thus ensuring continued restriction of pulmonary circulation while alleviating excessive cyanosis. To maintain desired saturations, the mean $\mathrm{PAB}$ dilation required to accommodate somatic growth was $45 \pm 7 \%$, again highlighting the advantage of progressive percutaneous dilation after one surgical procedure as an alternative to multiple surgical procedures for appropriate titration of the band or removal of the band entirely to avoid excessive cyanosis and thus to tolerate a degree of pulmonary overcirculation.

Because this study noted only short-term follow-up evaluation of these patients, long-term effects into adulthood are unknown. Also, the small number of procedures limits our study, thus necessitating further studies and larger series.

The surgical technique described in this report is our current standard method of PAB placement on the main pulmonary artery whether the band is expected to require further enlargement or not. The surgical and interventional techniques outlined in this report represent the marriage of advances in interventional technology with traditional surgical concepts modified to fit current treatment algorithms. We believe the technique described in this report provides a safe and effective method for managing the first few months of life of small infants born with complex cardiac defects not suitable for safe early primary complete repair.

Continued experience with PABBD in our laboratory will allow for the long-term assessment of patients who have undergone the procedure as well as further experience with more patients, including any possible complications that may occur. Our additional understanding of these and other aspects of PABBD will allow for the submission of further suggestions in the future.

\section{Conclusion}

According to the study findings, PABBD is feasible and, based on this small experience, appears to be a safe method for augmenting pulmonary blood flow in a controlled fashion. The PABBD technique may be used as an alternative to surgical PAB readjustment. This method can compensate for somatic growth without having to tolerate unacceptable cyanosis and without further surgery to adjust or possibly remove the band.

Open Access This article is distributed under the terms of the Creative Commons Attribution Noncommercial License which permits any noncommercial use, distribution, and reproduction in any medium, provided the original author(s) and source are credited.

\section{References}

1. Berman W Jr, Fripp RR, Yabek SM, Raisher BD (1999) Disruption of pulmonary artery band by balloon dilatation catheter. Pediatr Cardiol 20:308

2. Bjørnstad PG, Lindberg HL, Smevik B, Rian R, Sørland SJ, Tjønneland S (1990) Balloon debanding of the pulmonary artery. Cardiovasc Intervent Radiol 13:300-303

3. Bonnet D, Patkaï J, Tamisier D, Kachaner J, Vouhé P, Sidi D (1999) A new strategy for the surgical treatment of aortic coarctation associated with ventricular septal defect in infants using an absorbable pulmonary artery band. JACC 34(3):886-970

4. Bonnet D, Corno AF, Sidi D, Sekarski N, Beghetti M, SchulzeNeick I (2004) Early clinical results of telemetric adjustable pulmonary artery banding FloWatch-PAB. Circulation 110(Suppl):158-163

5. Choudhary SK, Talwar S, Airan B, Mohapatra R, Juneja R, Kothari SS, Saxena A, Venugopal P (2006) A new technique of percutaneously adjustable pulmonary artery banding. J Thorac Cardiovasc Surg 31:621-624

6. Corno AF, Bonnet D, Sekarski N, Sisi D, Vouché P, von Segesser LK (2003) Remote control of pulmonary blood flow: initial clinical experience. J Thorac Cardiovasc Surg 126:317-322

7. Corno AF, Ladusans EF, Pozzi M, Serr S (2007) FloWatch versus conventional pulmonary artery banding. $\mathrm{J}$ Thorac Cardiovasc Surg 134:1413-1420 
8. Horowitz MD, Culpepper WS, Williams LC III, Sungaard Riise K, Ochsner JI (1989) Pulmonary artery banding: analysis of 25year experience. Ann Thorac Surg 48:444-450

9. Kron IL, Nolan SP, Flanagan TL, Gutgesell HP, Muller WH (1989) Pulmonary artery banding revisited. Ann Surg 209: 642-647

10. Lindberg H, Smevik B, Bjørnstad PG, Rian R, Foerster A, Tjønneland S, Sorland S, Sponheim S (1988) Balloon dilation of pulmonary artery banding in dogs: an experimental study. Cardiovasc Intervent Radiol 11:150-154

11. Michel-Behnke I, Akintuerk H, Valeske K, Thul J, Mueller M, Dreyer Schranz (2005) Pseudoaneurysm of the pulmonary trunk after placement of an adjustable pulmonary artery banding device (FloWatch-PAB) in a patient with muscular septal defect. J Thorac Cardiovasc Surg 130:894-895

12. Muller WH Jr, Dammann FJ Jr (1953) The treatment of certain congenital malformations of the heart by the creation of pulmonic stenosis to reduce pulmonary hypertension and excessive pulmonary blood flow: a preliminary report. Surg Gynecol Obstet 95:129-213

13. Mullins CE, Latson LA, Neches WH et al (1990) Balloon dilatation of miscellaneous lesions: results of valvuloplasty and angioplasty of congenital anomalies registry. Am J Cardiol 65:802-803

14. Norwood WI, Pigott JD (1988) Recent advances in congenital cardiac surgery. Clin Perinatol 15:713-719

15. Sekarski N, Fridez P, Corno AF, von Segesser LK, Meijboom E (2004) Doppler-guided regulation of a telemetrically operated adjustable pulmonary banding system. J Am Coll Cardiol 44:1087-1094

16. Smevik B, Lindberg H, Tjønneland S, Bjørnstad PG, Sørland SJ, Foerster A (1988) Technical-note: in vitro balloon dilation of the banded pulmonary artery. Cardiovasc Intervent Radiol 11: $155-156$

17. Venugopal PS, Hayes N, Simpson J, Dreyer Anderson (2009) Transection with pseudoaneurysm formation of the pulmonary trunk after placement of an adjustable pulmonary artery banding device (FloWatch-PAB) in a patient with residual muscular ventricular septal defect. J Thorac Cardiovasc Surg 139:e103e104

18. Vince DJ, Culham G, Taylor G (1987) Development of a prosthesis for banding of an artery capable of stage dilation by intraluminal balloon dilator: an experimental investigation. J Thorac Cardiovasc Surg 93:628-631 